\title{
Analysis of ROC: The value of HPV16 E6 protein in the diagnosis of early stage cervical carcinoma and precancerous lesions
}

\author{
LI SUN $^{1 *}$, SHUBIN XU ${ }^{2 *}$, LEI LIANG ${ }^{1}$, LIANG ZHAO $^{2}$ and LEI ZHANG ${ }^{1}$ \\ Departments of ${ }^{1}$ Gynecology and ${ }^{2}$ Vascular Surgery, Bethune International Peace Hospital, \\ Shijiazhuang, Hebei 050081, P.R. China
}

Received March 1, 2016; Accepted July 11, 2016

DOI: $10.3892 / \mathrm{ol} .2016 .4844$

\begin{abstract}
Cervical carcinoma is a multifactorial malignant tumor and diagnosis is therefore crucial. The aim of the present study was to examine the value of E6 oncoprotein, in human papillomavirus type 16 (HPV16), in the diagnosis of early stage cervical carcinoma and precancerous lesions. Receiver operating characteristic curve was used to analyze accuracy of diagnosis. A total of 124 patients infected with HPV16 were included in the study. The patients had an average age of $46.7 \pm 6.9$ years and duration of disease of $10.5 \pm 3.4$ months. To determine the expression level of HPV16 E6 the immunohistochemical Elivision method was performed. Proportion/horizon positive cells were used to count the cells, and pathologic diagnosis was employed for analysis of the results. The average follow-up time was $2.6 \pm 0.7$ years. Sensitivity and specificity of diagnosing HPV16 E16 at 1 and 2 years, respectively, were calculated. The diagnostic rate of cervical carcinoma increased with time, and the positive expression of HPV16 E6 was also increased with the development of the disease. Differences among groups were statistically significant $(\mathrm{P}<0.05)$. Sensitivity, specificity and accuracy (AUC) of HPV16 E6 diagnosis improved with time, and the differences were statistically significant $(\mathrm{P}<0.05)$. Thus, HPV16 E6 oncoprotein can be used as an indicator with good sensitivity and specificity to diagnose early cervical carcinoma and precancerous lesions. The results therefore showed that accuracy increased with the development of the disease.
\end{abstract}

\section{Introduction}

Cervical carcinoma is one of the most malignant tumors in women (1). There are an estimated 4.6 million new patients

Correspondence to: Dr Shubin Xu, Department of Vascular Surgery, Bethune International Peace Hospital, 398 Zhongshan West Road, Shijiazhuang, Hebei 050081, P.R. China

E-mail:shubin_xu1@163.com

*Contributed equally

Key words: human papillomavirus type 16 E6 protein, cervical carcinoma, precancerous lesions, receiver operating characteristic annually, with a mortality rate of $20-35 \%$ (2). The occurrence and development of cervical carcinoma have obvious stages, lasting 5-10 years, including cervical squamous epithelium, atypical hyperplasia (mild, moderate and severe), cancer in situ, and early invasive to invasive carcinoma (3).

Prior studies suggested that the persistent infection rate of human papillomavirus type 16 (HPV16) ranges from 50 to $75 \%$, which may be an important factor of neoplasia (4). Identifying a high-risk population in the early stage and carrying out regular dynamic monitoring can promote diagnosis, increase the chance of treatment and play an important role in improving the prognosis. Although high-risk populations can be identified by multifactorial analysis, including age and time of gravidity or parity, risk levels and progression of the disease remain to be determined (5). Recent studies mainly focused on screening the specific oncogene and oncoprotein expression in the different stages of cervical lesions. In those studies, HPV16 E6 or E7 were used as markers with higher sensitivity and specificity to diagnose cervical carcinoma $(6,7)$. Nevertheless the boundary value of diagnosis and accuracy of identifying high-risk populations of early stage cervical carcinoma were not provided.

The aim of the present study was to examine the value of E6 oncoprotein, in HPV16, in the diagnosis of early stage cervical carcinoma and precancerous lesions. In addition, we followed up the population at high risk and used the receiver operating characteristic (ROC) curve to obtain the boundary value and accuracy of diagnosis in order to provide valuable statistical analyses for clinical studies. The results showed HPV16 E6 oncoprotein serves as an indicator with good sensitivity and specificity in the diagnosis of early cervical carcinoma and precancerous lesions. Thus, accuracy increased with the development of the disease

\section{Materials and methods}

Subjects. From January, 2012 to June, 2013, 124 cases of female patients diagnosed with persistent HPV16 infection were selected. Inclusion criteria for the study were: i) age $\geq 18$ and $<75$ years; ii) patients were diagnosed for the first time and did not receive treatments; and iii) clinical information of patients were complete. Exclusion criteria for the study were: i) pregnant women, lactating women and those during menstrual period; ii) cases with other genito-urinary 
system diseases and those with surgery and trauma history; and iii) cases with inaccurate experimental images were also excluded. The average age of patients was $46.7 \pm 6.9$ years and the average duration of infection by HPV16 was $10.5 \pm 3.4$ months. The average time of gravidity or parity was $1.2 \pm 0.5$, and the average menopausal age was $48.9 \pm 3.3$ years, and usage rate of contraceptives was $45.8 \%$.

This study was approved by the Ethics Committee of the Bethune International Peace Hospital (Hebei, China). Informed consent of patients and their relatives was also obtained.

Observation indicators and test methods. A dynamic follow-up database was established up to January 2016, and average follow-up time was $2.6 \pm 0.7$ years. The immunohistochemical Elivision method was used to detect the HPV16 E6 protein expression at different time points (first day, one year after follow up and two years after follow up). Pathologic diagnosis was used to analyze the results and clinical staging criteria, revised by the International Federation of Gynecology and Obstetrics (FIGO) in 2000, were used with regard to cervical intraepithelial neoplasia (CIN) III, cancer in situ, early invasive and invasive carcinoma as cervical carcinoma, and others including precancerous lesions and normal tissues.

Main experimental reagents. Mouse anti-human HPV16 E6 monoclonal antibody (SC-460; dilution: 1:50) was purchased from Santa Cruz Biotechnology, Inc., Santa Cruz, CA, USA), and immunohistochemical Elivision ${ }^{\mathrm{TM}}$ plus kit and DAB developer were purchased from Beijing Zhongshan Jinqiao Biotechnology Co., Ltd., Beijing, China. To prepare phosphatebuffered saline (PBS) buffer solution $29 \mathrm{~g}$ of $\mathrm{Na}_{2} \mathrm{HPO}_{4} \cdot 12 \mathrm{H}_{2} \mathrm{O}$, $3 \mathrm{~g} \mathrm{NaH} \mathrm{PO}_{4} \cdot 2 \mathrm{H}_{2} \mathrm{O}$ and $85 \mathrm{~g}$ of $\mathrm{NaCl}$ were mixed and distilled water up to $1,000 \mathrm{ml}$ was added. The buffer was used to prepare 0.1 M PBS buffer solution with pH 7.4 (the solution was diluted 10 times using distilled water, to obtain $0.01 \mathrm{M}$ PBS solution buffer with $\mathrm{pH}$ 7.4).

Main instruments. The following instruments were purchased: Tissue embedding machine (Bnu-III, domestic; Biosharp, Hefei, China), tissue processor (Tissue-Tek; Sakura Finetechnical Co., Tokyo, Japan), paraffin slicing machine (Leica-2025; Leica Microsystems, Wetzlar, Germany), adjustable micropipettor (Gilson Inc., Villiers le Bel, France), and light microscope (Olympus, Tokyo, Japan).

Main steps. i) Formaldehyde (10\%) was used to fix tissue samples. Samples were sliced into $0.5 \mathrm{~cm}$ sections and placed in AF liquid for fixation (1 h). The samples were then transferred to $95 \%$ alcohol (overnight), followed by dehydration (using absolute alcohol and xylene) and then placed in impregnated wax boxes (Biosharp). The samples were embedded and paraffin blocks were constructed. ii) Elivision method was employed in immunohistochemical staining. PBS was used as a negative control, and a positive control image was purchased from Beijing Zhongshan Jinqiao Biotechnology Co., Ltd. Sections $(4 \mu \mathrm{m})$ were prepared and then adhered to slide glass of polylysine attached membrane at $60^{\circ} \mathrm{C}$ and left overnight. Xylene was used to dewax the sections conventionally and graded ethanol to dehydrate, and running and distilled water were used to rinse the samples three times in PBS (3 times for 3 min each time). The samples were soaked in citrate buffer solution ( $\mathrm{pH}$ 6.0). High pressure repairing antigen was employed, and the samples were cooled to $20^{\circ} \mathrm{C}$. One drop of $3 \% \mathrm{H}_{2} \mathrm{O}_{2}$ was added to each section, and the samples were incubated at room temperature for $10 \mathrm{~min}$ to inhibit endogenous oxidase activity. PBS solution was used to wash the samples (3 times for 3 min each time). Subsequently, $50 \mu \mathrm{l}$ primary antibody was added to each section (working concentration of anti-HPV16 E6 protein was 1:50), followed by incubatation at room temperature for $10 \mathrm{~min}$. PBS solution was used for washing (3 times for $3 \mathrm{~min}$ each). Then one drop of reagent A (polymer enhancer) was add to each section, and the samples were incubated at room temperature for $20 \mathrm{~min}$. After rinsing with PBS (3 times for 3 min each time), one drop of reagent B (enzyme labeled anti-mouse polymer) was added to each section. The sections were then incubated at room temperature for $30 \mathrm{~min}$.

After washing with PBS ( 3 times for 3 min each time) one drop or $50 \mu \mathrm{l}$ of freshly prepared DAB solution was added to each section. The samples were washed under running water, hematoxylin was added to restain the samples for $1 \mathrm{~min}$ and the sections were washed under running water and PBS solution. Gradient ethanol was used to dry and dehydrate the sections, which became transparent in xylene and were fixed using neutral balata.

Interpretation of the results. Presence of brown particles in the cell, revealed the expression of HPV16 E6 protein. At a magnification of $\mathrm{x} 400$ five horizons were randomly selected, 200 tumor cells were counted (total of 1,000 tumor cells), and the proportion/horizon of positive cells was counted.

Statistical methods. SPSS 19.0 software (IBM, Armonk, NY, USA) was used to analyze data. Measurement data were presented as mean \pm standard deviation, and one-way ANOVA was used for comparisons among groups. Enumeration data were used to indicate cases or (\%), and the $\chi^{2}$ test was used to make comparisons among groups. Area under curve (AUC) of ROC was used to compare accuracy of diagnosis. $\mathrm{P}<0.05$ was used to indicate statistically significant results.

\section{Results}

Comparisons of the positive expression of HPV16R6 among groups. HPV16 E6 protein expression increased with the development of the disease. Twenty-five positive cases $(20.2 \%)$ were identified at the inception of the study, 57 cases $(46.0 \%)$ at 1 year after follow-up, and 70 cases $(56.5 \%)$ at 2 years after follow-up. Differences among the groups were of statistical significance $(\mathrm{P}<0.05)$ (Table I).

ROC analysis diagnosing HPV16 E6. The AUC of diagnosis at the inception of the study was 0.635 , and $95 \%$ CI was $0.375-0.821$; sensitivity was $62.5 \%$, while specificity was $72.4 \%$. The AUC of diagnosis 1 year after follow-up was 0.719 , and $95 \%$ CI was $0.462-0.873$; sensitivity was $72.6 \%$, while specificity was $82.4 \%$. The AUC of diagnosis 2 years after follow-up was 0.821 , and $95 \%$ CI was $0.488-0.893$; sensitivity was $82.2 \%$, while specificity was $89.7 \%$. Sensitivity, 
Table I. Comparisons of positive expression of HPV16R6 among groups (proportioin/horizon).

\begin{tabular}{|c|c|c|c|c|c|c|}
\hline \multirow[b]{2}{*}{ Group } & \multicolumn{2}{|c|}{ At inception of the study } & \multicolumn{2}{|c|}{1 year after follow-up } & \multicolumn{2}{|c|}{2 years after follow-up } \\
\hline & No. of cases & $\begin{array}{l}\text { Positive } \\
\text { expression }\end{array}$ & No. of cases & $\begin{array}{l}\text { Positive } \\
\text { expression }\end{array}$ & No. of cases & $\begin{array}{l}\text { Positive } \\
\text { expression }\end{array}$ \\
\hline Invasive carcinoma & 3 & $72.5 \pm 13.2$ & 10 & $76.4 \pm 14.3$ & 16 & $79.3 \pm 15.2$ \\
\hline Early invasive carcinoma & 9 & $48.6 \pm 10.4$ & 22 & $52.3 \pm 12.2$ & 24 & $54.6 \pm 13.2$ \\
\hline CIN III and cancer in situ & 13 & $25.5 \pm 8.7$ & 25 & $24.6 \pm 7.5$ & 30 & $25.5 \pm 6.7$ \\
\hline CIN I and II & 59 & $13.6 \pm 4.3$ & 40 & $17.7 \pm 4.6$ & 36 & $18.2 \pm 4.3$ \\
\hline Normal cervix & 40 & $3.7 \pm 1.2$ & 27 & $3.9 \pm 1.2$ & 18 & $3.7 \pm 1.3$ \\
\hline F-test & \multicolumn{2}{|c|}{12.635} & \multicolumn{2}{|c|}{13.462} & \multicolumn{2}{|c|}{15.624} \\
\hline P-value & \multicolumn{2}{|c|}{$<0.001$} & \multicolumn{2}{|c|}{$<0.001$} & \multicolumn{2}{|c|}{$<0.001$} \\
\hline
\end{tabular}

HPV16, human papillomavirus type 16; CIN, cervical intraepithelial neoplasia.
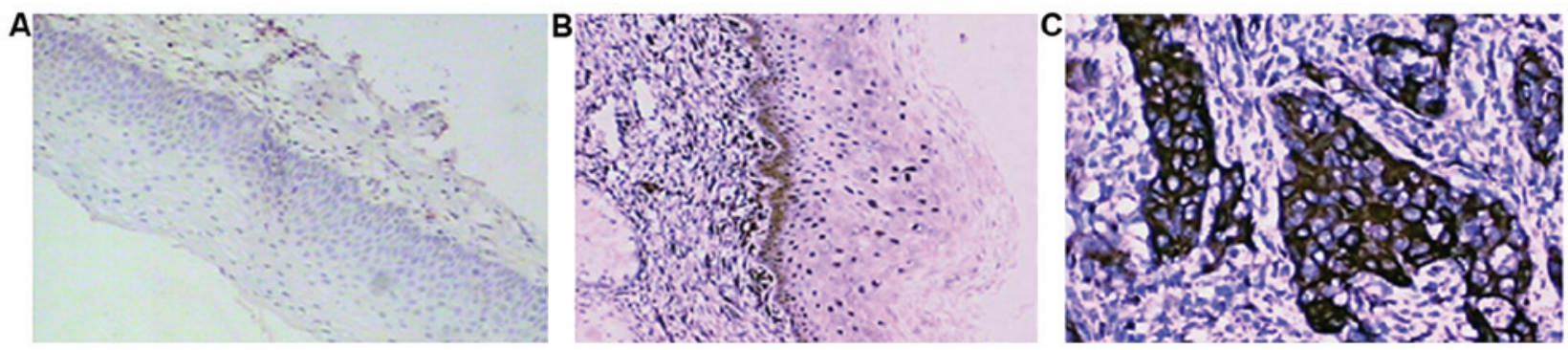

Figure 1. Elivision staining of HPV16 E6 protein. (A) Normal cervical tissue, (B) CIN tissue and (C) cervical carcinoma. HPV16, human papillomavirus type 16 ; CIN, cervical intraepithelial neoplasia.

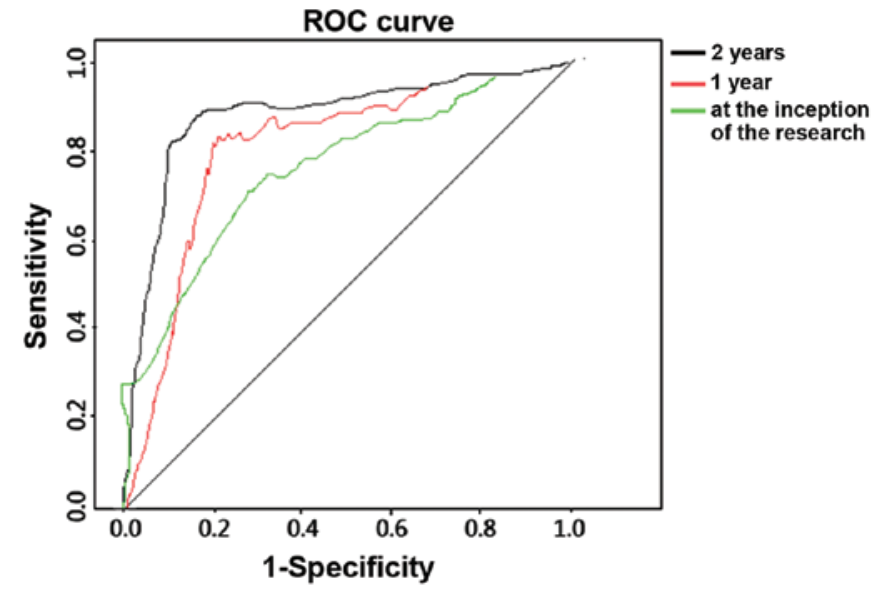

Figure 2. ROC analysis of diagnosing HPV16E6. HPV16, human papillomavirus type 16 ; ROC, receiver operating characteristic.

specificity and accuracy of diagnosing HPV16 E6 increased over time. The differences were of statistical significance $(\mathrm{P}<0.05)$ (Fig. 2).

\section{Discussion}

The HPV16 E6 gene is located within nucleotides 83-559 on the HPV16 viral genome, and is composed of 477 nucleotides. E6 protein is a small and basic protein with two zinc finger motifs (8). The presence of E6 has been shown to be closely associated with malignant transformation, transcriptional activation, and interactions between cells (8). HPV16E6 is a major protein in the virus life cycle, and continuous expression of the E6 protein is key to the cause of immortalization, malignant transformation and malignant phenotype maintenance of host cells and the progression of disease after HPV16 DNA integrates into the host cell genome (9).

Previous findings showed that E6 protein can trigger the degradation of tumor-inhibiting factors such as P53 and $\mathrm{pRB}$. It mediates cell apoptosis by forming complexes with related proteins of ubiquitin ligase E6 (10) and the activating transcription of the human telomerase catalytic subunit gene. E6 protein decreases the stability of hosts' chromosomes and promotes immortalization of host cells (11). Expression of E6 protein inhibits the promoter activity of E-cadherin in epithelium and restrains cytokines mediated by the transcript of E-cadherin to adhere to epidermal antigen-presenting cells, both of which promote the occurrence of immune escape of virus (12). Interacting with Death domain-associated protein (Daxx), E6 protein can inhibit promoter activity of Daxx, decrease Daxx protein expression and prevent apoptosis (13). E6 protein may also interact with host cell transcription factors such as cytokines of activator protein-1, TNF- $\alpha$ and IL-1 $\beta$. E6 plays an important role in the development of cervical carcinoma (14). The HPV16 E6 gene locus mutation is associated with persistent viral infection, high-grade cervical lesions and squamous carcinoma of the cervix (15). Upregulation of E6 stimulates cell multiplication and inhibits cell differentiation 
at the same time (16). Generally speaking, it can be said that E6 protein plays an important role in the carcinogenesis of HPV16.

The findings suggest that the diagnostic rate of cervical carcinoma increased with time. We detected 25 positive cases $(20.2 \%)$ at the inception of the study, 57 cases $(46.0 \%)$ at 1 year after follow-up, and 70 cases $(56.5 \%)$ at 2 years after follow-up. These results suggested that persistent HPV16 infection is an important factor in the occurrence and development of cervical carcinoma. The positive expression of HPV16 E6 increased as the disease developed, suggesting that HPV16 E6 was highly expressed in cervical carcinoma and its presence was positively correlated with the tumor stage. Sensitivity, specificity and accuracy of diagnosis using E6 improved with time and the sensitivity and specificity at 1 and 2 years after follow-up were up to $75 \%$, and the accuracy was $70 \%$. Sensitivity, specificity and accuracy results suggested that the E6 oncoprotein can be used as an indicator with acceptable sensitivity and specificity to diagnose early cervical carcinoma and precancerous lesions. The accuracy increased as the disease developed.

In summary, efforts should be focused on the high-risk populations for persistent infection and offer dynamic monitoring analyses for this group. HPV16 E6 protein had an important value of identifying early cervical carcinoma, and it provided accurate quantitative test data at the same time to distinguish lesions of different stages, both of which provided new methods for clinical practices. For future studies, we suggest using larger samples and randomized clinical control studies.

\section{References}

1. Mocarska A, Staroslawska E, Zelazowska-Cieślińska I, Łosicki M, Stasiewicz D, Kieszko D and Burdan F: Epidemiology and risk factors of the cervical squamous cell carcinoma. Pol Merkur Lekarski 33: 101-106, 2012 (In Polish).

2. Yung KW, Yung TT, Chung CY, Tong GT, Liu Y, Henderson J, Welbeck D and Oseni S: Principles of cancer staging. Asian Pac J Surg Oncol 1: 1-16, 2015.

3. Chiappetta C, Lendaro E, Cacciotti J, Zaralli R, Puggioni C, Migliore G, Petrozza V, Rocca CD and Di Cristofano C: The 16,18 , and 45 HPV infection in high grade squamous cervical lesions in primary hr-HPV test screening program. Eur J Gynaecol Oncol 36: 722-725, 2015.

4. Smith JS, Lindsay L, Hoots B, Keys J, Franceschi S, Winer R and Clifford GM: Human papillomavirus type distribution in invasive cervical cancer and high-grade cervical lesions: a meta-analysis update. Int J Cancer 121: 621-632, 2007.
5. Mzarico E, Gómez-Roig MD, Guirado L, Lorente $\mathrm{N}$ and Gonzalez-Bosquet E: Relationship between smoking, HPV infection, and risk of Cervical cancer. Eur J Gynaecol Oncol 36: 677-680, 2015.

6. Zacapala-Gómez AE, Del Moral-Hernández O, VillegasSepúlveda N, Hidalgo-Miranda A, Romero-Córdoba SL, Beltrán-Anaya FO, Leyva-Vázquez MA, Alarcón-Romero LC and Illades-Aguiar B: Changes in global gene expression profiles induced by HPV 16 E6 oncoprotein variants in cervical carcinoma C33-A cells. Virology 488: 187-195, 2016.

7. Poljak M, Kocjan BJ, Oštrbenk A and Seme K: Commercially available molecular tests for human papillomaviruses (HPV): 2015 update. J Clin Virol 76 (Suppl 1): S3-S13, 2015.

8. Zanier K, ould M'hamed ould Sidi A, Boulade-Ladame C, Rybin V, Chappelle A, Atkinson A, Kieffer B and Travé G: Solution structure analysis of the HPV16 E6 oncoprotein reveals a self-association mechanism required for E6-mediated degradation of p53. Structure 20: 604-617, 2012.

9. Zhang G, Sun L, Li Z, Si L, Song T, Huang C and Zhang W: HPV-16E6 can induce multiple site phosphorylation of $\mathrm{p} 53$. Oncol Rep 21: 371-377, 2009.

10. Bernard X, Robinson P, Nominé Y, Masson M, Charbonnier S, Ramirez-Ramos JR, Deryckere F, Travé G and Orfanoudakis G: Proteasomal degradation of p53 by human papillomavirus E6 oncoprotein relies on the structural integrity of p53 core domain. PLoS One 6: e25981, 2011.

11. Lee CJ, Suh EJ, Kang HT, Im JS, Um SJ, Park JS and Hwang ES: Induction of senescence-like state and suppression of telomerase activity through inhibition of HPV E6/E7 gene expression in cells immortalized by HPV16 DNA. Exp Cell Res 277: 173-182, 2002.

12. D'Costa ZJ, Jolly C, Androphy EJ, Mercer A, Matthews CM and Hibma MH: Transcriptional repression of E-cadherin by human papillomavirus type 16 E6. PLoS One 7: e48954, 2012.

13. Dionne KR, Zhuang Y, Leser JS, Tyler KL and Clarke P: Daxx upregulation within the cytoplasm of reovirus-infected cells is mediated by interferon and contributes to apoptosis. J Virol 87: 3447-3460, 2013.

14. White EA, Kramer RE, Tan MJ, Hayes SD, Harper JW and Howley PM: Comprehensive analysis of host cellular interactions with human papillomavirus E6 proteins identifies new E6 binding partners and reflects viral diversity. J Virol 86: 13174-13186, 2012.

15. Niebler M, Qian X, Höfler D, Kogosov V, Kaewprag J, Kaufmann AM, Ly R, Böhmer G, Zawatzky R, Rösl F, et al: Post-translational control of IL-1 $\beta$ via the human papillomavirus type 16 E6 oncoprotein: a novel mechanism of innate immune escape mediated by the E3-ubiquitin ligase E6-AP and p53. PLoS Pathog 9: e1003536, 2013.

16. McCloskey R, Menges C, Friedman A, Patel D and McCance DJ: Human papillomavirus type 16 E6/E7 upregulation of nucleophosmin is important for proliferation and inhibition of differentiation. J Virol 84: 5131-5139, 2010. 